\title{
Absorption Spectrum of $\mathrm{As}_{2}$ Further Analysis of the $\mathrm{A} \rightarrow \mathrm{X}$ System and Observation of New Electronic States
}

\author{
Abdel Mooti Sibaï *, Pierre Perdigon, and Ari Topouzkhanian \\ Laboratoire de Spectrométrie Ionique et Moléculaire (associé au C.N.R.S.), \\ Université Claude Bernard, Lyon I \\ (Z. Naturforsch. 29 a, 429-435 [1974] ; received 17 November 1973)

\begin{abstract}
Within the study of the interaction between $\mathrm{A}$ and $\mathrm{B}$ states of $\mathrm{As}_{2}$ molecule, a high resolution analysis of 16 absorption bands with $11 \leqq v^{\prime} \leqq 17$ in the $\mathrm{A} \leftarrow \mathrm{X}$ system has been performed. The following constants are proposed for the A state: $T_{00}=40145.9 \mathrm{~cm}^{-1}, \omega_{\mathrm{e}}=262.7 \mathrm{~cm}^{-1}, \omega_{\mathrm{e}} x_{\mathrm{e}}=$ $0.48 \mathrm{~cm}^{-1}, \quad B_{\mathrm{e}}=0.0797 \mathrm{~cm}^{-1}, \quad D_{\mathrm{e}} \cong 3 \times 10^{-8} \mathrm{~cm}^{-1}, \quad \alpha_{\mathrm{e}}=0.00031 \mathrm{~cm}^{-1}, \quad r_{\mathrm{e}}=2.374 \AA$. Three new vibronic levels have been discovered in the $42400-44500 \mathrm{~cm}^{-1}$ energy range, either directly or by the perturbations they induce in A levels.
\end{abstract}

\section{Introduction}

The absorption spectrum of the $\mathrm{As}_{2}$ molecule in the ultraviolet region $(2200-2750 \AA)$ has been recorded for the first time in 1934 by Gibson and MacFarlane ${ }^{1}$. They have classified almost all the observed bands in one electronic system, namely $\mathrm{A} \leftarrow \mathrm{X}$, which on the analogy of the $\mathrm{N}_{2}$ and $\mathrm{P}_{2}$ molecules, was assigned to a ${ }^{1} \Sigma_{\mathrm{u}}{ }^{+}-{ }^{1} \Sigma_{\mathrm{g}}{ }^{+}$transition. Recently, this absorption spectrum has been extended to the vacuum ultraviolet region by Topouzkhanian and Sibai ${ }^{2}$, down to $1775 \AA$. Most of the new bands belong to the $\mathrm{A} \leftarrow \mathrm{X}$ system, and the others have been arranged into two new $\mathrm{F} \leftarrow \mathrm{X}$ and $\mathrm{G} \leftarrow \mathrm{X}$ systems. On the other hand, Donovan and Strachan ${ }^{3}$ observed absorption bands of $\mathrm{As}_{2}$ molecule as far as $1365 \AA$, following the flash photolysis of $\mathrm{AsH}_{3}$. The latter have been ascribed to the $\mathrm{A} \leftarrow \mathrm{X}$ system and to seven others, two of them $(f \leftarrow X$ and $E \leftarrow X)$ being identical, respectively, to the $\mathrm{F} \leftarrow \mathrm{X}$ and $\mathrm{G} \leftarrow \mathrm{X}$ systems of Topouzkhanian and Sibai. The corresponding transitions have been interpreted as Rydberg in type, except for $\mathrm{f} \leftarrow \mathrm{X}$ and $\mathrm{A} \leftarrow \mathrm{X}$.

This last system has been observed very strongly in emission between 2300 and $5600 \AA$ by Almy and Kinzer ${ }^{4,5}$, but bands with $v^{\prime} \geqq 10$ do not appear, except those for which $v=14$. Accordingly, a predissociation of the A state is to be expected for vibrational levels beyond $v=9\left(T_{0(v=9)}=42577.7 \mathrm{~cm}^{-1}\right)$. Another system, $\mathrm{B} \rightarrow \mathrm{X}$, lies in the same spectral region, but Almy and Kinzer assumed that the $\mathrm{B}$ state dissociates near $42600 \mathrm{~cm}^{-1}$, i. e. the energy at which A predissociates. It must be emphasized that

Reprint requests to P. Perdigon, Laboratoire de Spectrométrie Ionique et Moléculaire, Université de Lyon I, 43, strong irregularities appear in $\Delta \mathrm{G}$ intervals of the $\mathrm{A}$ and $\mathrm{B}$ states, which indicates the occurence of perturbations. A rotational analysis of numerous bands of $\mathrm{A} \rightarrow \mathrm{X}$ and $\mathrm{B} \rightarrow \mathrm{X}$ systems has been carried out by Perdigon, Martin and D'Incan ${ }^{6,7,8}$. It led to the conclusion that $\mathrm{A}$ and $\mathrm{B}$ states are of ${ }^{1} \Sigma_{\mathrm{u}}{ }^{+}$(or case $\mathrm{c}-\mathrm{O}_{\mathrm{u}}{ }^{+}$) symmetry, and confirmed that the observed perturbations are due to an interaction of these two states, as previously suggested by Almy and Kinzer.

As the treatment of this interaction requires as far as possible a complete knowledge of A and B levels, it appeared quite necessary to get information about the A levels with $v>9$. The purpose of the present work was to perform a rotational analysis of absorption bands with $10 \leqq v \leqq 17$, which have been recorded under high resolution. During this investigation, three hitherto unknown vibronic levels have been discovered, directly or through the perturbations they induce in A levels.

\section{Experimental Conditions}

The absorption tube was prepared in a previously described way ${ }^{2}$, and the source of continuous ultraviolet light was of the Finkelstein type ${ }^{9}$. Spectra have been photographed with the 4-m asymmetric Czerny-Turner grating vacuum spectrograph ${ }^{10}$ of the University College London, on Kodak 101-01 or SWR films. The exposure times varied between 5 and 60 minutes. The slit width was $30 \mu$, which allowed a resolving power of about 300000 , the reciprocal dispersion being $0.1 \AA / \mathrm{mm}$. The rotational lines have been calibrated against $\mathrm{Fe}$ atomic lines from a hollow cathode source. It is considered

boulevard du 11 novembre 1918, 69621 Villeurbanne, France. 
that, for sharp lines, the errors do not exceed $\pm 0.03 \mathrm{~cm}^{-1}$.

\section{Results}

All the investigated bands consist of only $\mathrm{P}$ and $\mathrm{R}$ branches, which present an intensity alternation, the lines with odd values of $J$ being the strongest. As $B_{\mathrm{e}}, \alpha_{\mathrm{e}}, \gamma_{\mathrm{e}}$ and $D_{\mathrm{e}}$ constants of the $\mathrm{X}^{1} \sum_{\mathrm{g}}{ }^{+}$state are well known ${ }^{6}, J$-values of each $\mathrm{P}$ and $\mathrm{R}$ line have been assigned with the help of classical combination differences. Least-squares fittings on the term values of the upper levels of the transitions were used to determine the $T_{0 \mathrm{v}}, B^{\prime}$ and $D^{\prime}$ constants.

$$
A(v=10) \text { level }
$$

Whereas $(10-0),(10-1)$ and $(10-2)$ heads were observed on low resolution spectrograms ${ }^{2}$, they are not perceptible on high resolution films. At $42412.7 \mathrm{~cm}^{-1}$, the wavenumber at which the (10-1) head is to be expected, it seems that a very weak

Table I. Wavenumbers for $(11-0)$ and $(11-1)$ bands of $\mathrm{A} \leftarrow \mathrm{X}$.

\begin{tabular}{|c|c|c|c|c|}
\hline \multirow[t]{2}{*}{$J$} & \multicolumn{2}{|c|}{$(11-0)$} & \multicolumn{2}{|c|}{$(11-1)$} \\
\hline & $P(J)$ & $R(J)$ & $P(J)$ & $R(J)$ \\
\hline 7 & 092.09 & & & 42667.82 \\
\hline 8 & & & 42664.93 & \\
\hline 9 & 90.83 & & 64.37 & 67.15 \\
\hline 10 & 89.84 & & 63.61 & \\
\hline 11 & & & 62.89 & 66.31 \\
\hline 12 & 88.10 & & 62.00 & 65.78 \\
\hline 13 & 87.15 & & 61.23 & 65.28 \\
\hline 14 & 86.22 & & 60.34 & 64.71 \\
\hline 15 & 85.18 & & 59.36 & 63.98 \\
\hline 16 & 84.12 & & 58.40 & 63.32 \\
\hline 17 & 82.97 & & 57.30 & 62.47 \\
\hline 18 & 81.80 & 43088.51 & 56.14 & 61.78 \\
\hline 19 & 80.51 & & 55.00 & 60.81 \\
\hline 20 & 72.22 & 86.66 & 53.74 & 59.85 \\
\hline 21 & 77.85 & 85.70 & 52.43 & 58.88 \\
\hline 22 & 76.51 & 84.67 & 51.12 & 57.83 \\
\hline 23 & 75.04 & 83.51 & 49.71 & 56.71 \\
\hline 24 & & 82.32 & 48.27 & 55.61 \\
\hline 25 & & 81.11 & 46.75 & 54.38 \\
\hline 26 & & & 45.26 & 53.12 \\
\hline 27 & & 78.34 & 43.65 & 51.88 \\
\hline 28 & & 77.12 & 42.01 & 50.42 \\
\hline 29 & & 75.71 & 40.36 & 49.03 \\
\hline 30 & & 74.17 & 38.44 & 47.48 \\
\hline 31 & & 72.66 & 36.59 & 45.92 \\
\hline 32 & & & 34.66 & 44.40 \\
\hline 33 & & & 32.69 & 42.76 \\
\hline 34 & & & 30.72 & 41.27 \\
\hline 35 & & & 28.61 & 39.24 \\
\hline 36 & & & & \\
\hline 37 & & & 23.89 & \\
\hline
\end{tabular}

absorption occurs. But, as for (10-0), all the rotational lines which appear down to $42160 \mathrm{~cm}^{-1}$ have been attributed to other transitions. Therefore, it is likely that all the rotational levels of this $(v=10)$ level are strongly predissociated.

$$
A(v=11) \text { level }
$$

(11-0) and (11-1) bands have been analyzed. Their heads are well defined and the structure is almost completely resolved. But it must be noted that all the lines are slightly diffuse, which indicates a weak predissociation, and they disappear completely for relatively low values of $J$. From $J=0$ to 37 , the $B$-value of the $(v=11)$ level is constant and equal to $0.0746 \mathrm{~cm}^{-1}$. Table I gives the measured wavenumbers for these two bands.

$$
A(v=12) \text { and unidentified } x_{1} \text { levels }
$$

Two series of lines, lying respectively near 43200 and $42700 \mathrm{~cm}^{-1}$, have been attributed to an unidentified $x_{1}$ level, which interacts with $A(v=12)$. These series may be grouped in branches, which are observed from $R(78)$ and $P(77)$ for the first one, from $R(85)$ and $P(87)$ for the second, and which disappear when the quantum number $J$ of the upper level reaches a value of about 100. Furthermore, in this range of $J$ values, the behaviour of the curve $R(J)-P(J)$ $4(J+1 / 2)$ versus $J$ is characteristic of the occurence of an interaction with another level (Figure 1). Since no line arising from this latter could

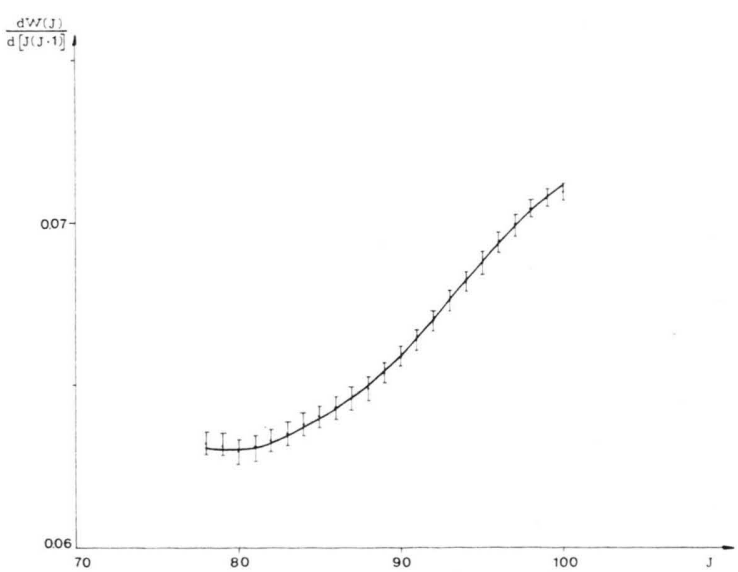

Fig. 1. $B(J)=\mathrm{d} W(J) / \mathrm{d} J(J+1)$ curve for $x_{1}$ level.

be observed, deperturbed constants $T_{0}$ and $B$ of the perturbed and perturbing levels have been calculated with the help of a method described by Massot, 
Goure and Figuet ${ }^{11}$, which requires the knowledge of the energies of only the perturbed level. The following values have been found:

$$
\begin{aligned}
T_{01} & =43354.6 \pm 1.6 \mathrm{~cm}^{-1}, \\
B_{1} & =0.0764 \pm 0.0001 \mathrm{~cm}^{-1}, \\
T_{02} & =43469.4 \pm 1.6 \mathrm{~cm}^{-1}, \\
B_{2} & =0.0633 \pm 0.0001 \mathrm{~cm}^{-1} .
\end{aligned}
$$

The interaction parameter $H_{12}$ is $11.7 \pm 0.8 \mathrm{~cm}^{-1}$ if the perturbation is homogeneous $\left(H_{12}\right.$ independent of $J$ ), which is the most probable case.

Comparison of these $B$-values with that obtained for the $A(v=11)$ level shows that $B_{1}$ is of the same magnitude as $B_{A(v=11)}$; furthermore, $T_{01}$ is nearly equal to the value $43350 \mathrm{~cm}^{-1}$ previously determined for $T_{0 A(v=12)}$. Therefore, there is no doubt that the two interacting levels labelled 1 and 2 are respectively $A(v=12)$ and a level $x_{1}$ which has not yet been observed. Figure 1 shows that the re-

\begin{tabular}{|c|c|c|c|c|}
\hline \multicolumn{5}{|c|}{$77 \quad 43228.79$} \\
\hline 78 & 22.13 & 43242.15 & & \\
\hline 79 & 15.99 & 36.07 & & \\
\hline 80 & & 29.80 & & \\
\hline 81 & 03.24 & 23.83 & & \\
\hline 82 & & 17.54 & & \\
\hline 83 & 190.51 & 11.61 & & \\
\hline 84 & 83.87 & 05.43 & & \\
\hline 85 & 77.30 & 199.14 & & 42774.63 \\
\hline 86 & & 92.88 & & \\
\hline 87 & 64.06 & 86.60 & 42739.67 . & 62.24 \\
\hline 88 & 57.45 & 80.35 & & 56.06 \\
\hline 89 & 50.80 & 74.03 & 26.13 & 49.77 \\
\hline 90 & 44.07 & 67.81 & 19.83 & 43.62 \\
\hline 91 & 37.45 & 61.73 & 13.31 & 37.46 \\
\hline 92 & 30.79 & 55.57 & 06.61 & 31.35 \\
\hline 93 & 24.19 & 49.45 & 00.07 & 25.30 \\
\hline 94 & 17.62 & 43.39 & 693.54 & 19.32 \\
\hline 95 & 11.11 & 37.39 & 87.09 & 13.35 \\
\hline 96 & 04.64 & 31.48 & 80.72 & 07.50 \\
\hline 97 & 098.26 & 25.57 & 74.36 & 01.75 \\
\hline 98 & 91.91 & 19.82 & 68.11 & 695.85 \\
\hline 99 & 85.56 & 13.97 & 61.92 & 90.27 \\
\hline 100 & 79.30 & 08.05 & 55.61 & 84.55 \\
\hline 101 & 73.47 & & 49.73 & \\
\hline 102 & 66.89 & & 43.67 & \\
\hline
\end{tabular}
corded rotational lines, which are listed in Table II, belong indeed to this $x_{1}$ level.

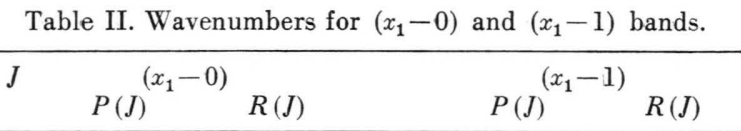

$$
A(v=13) \text { level }
$$

The rotational structure of (13-0), (13-1) and (13-2) bands appears only from $R(59)$ and $P(61)$ on. The first three lines of these branches are broad; then the lines are sharp, and become broad again beyond $R(78)$ and $P(80)$. They disappear com- pletely when the quantum number $J$ of the upper level reaches about 85 . For all the observed values of $J$ in this level, $B$ is constant $\left(0.0755 \mathrm{~cm}^{-1}\right)$, the centrifugal distortion constant $D$ being $3.8 \times$

\begin{tabular}{|c|c|c|c|c|}
\hline \multirow[t]{2}{*}{$J$} & \multicolumn{2}{|c|}{$(13-0)$} & \multicolumn{2}{|c|}{$(13-1)$} \\
\hline & $P(J)$ & $R(J)$ & $P(J)$ & $R(J)$ \\
\hline 59 & & $43519.64 \mathrm{~b}$ & & 43094.05 \\
\hline 60 & & $16.55 \mathrm{~b}$ & & 90.94 \\
\hline 61 & $43495.04 \mathrm{~b}$ & $13.47 \mathrm{~b}$ & 43069.45 & 87.71 \\
\hline 62 & $91.55 \mathrm{~b}$ & 10.29 & 65.93 & 84.76 \\
\hline 63 & $88.02 \mathrm{~b}$ & 07.07 & 62.58 & 81.68 \\
\hline 64 & 84.48 & 03.77 & 59.14 & 78.74 \\
\hline 65 & 80.82 & 00.47 & 55.49 & 75.08 \\
\hline 66 & 77.15 & 497.06 & 51.81 & 71.76 \\
\hline 67 & 73.40 & 93.63 & 48.13 & 68.35 \\
\hline 68 & 69.61 & 90.12 & 44.36 & 64.87 \\
\hline 69 & 65.75 & 86.57 & 40.56 & 61.39 \\
\hline 70 & 61.87 & 82.99 & 36.69 & 57.87 \\
\hline 71 & 57.94 & 79.35 & 32.83 & 54.23 \\
\hline 72 & 53.92 & 75.65 & 28.84 & 50.57 \\
\hline 73 & 49.88 & 71.86 & 24.84 & 46.87 \\
\hline 74 & 45.78 & 68.07 & 20.81 & 43.10 \\
\hline 75 & 41.60 & 64.22 & 16.69 & 39.26 \\
\hline 76 & 37.38 & 60.25 & 12.54 & 35.38 \\
\hline 77 & 33.09 & 56.30 & 08.29 & 31.45 \\
\hline 78 & 28.77 & $52.28 \mathrm{~b}$ & 04.01 & $27.48 \mathrm{~b}$ \\
\hline 79 & 24.41 & $48.18 \mathrm{~b}$ & 42999.63 & $23.45 \mathrm{~b}$ \\
\hline 80 & & $44.02 \mathrm{~b}$ & $95.32 \mathrm{~b}$ & $19.32 \mathrm{~b}$ \\
\hline 81 & & $39.78 \mathrm{~b}$ & $90.83 \mathrm{~b}$ & $15.17 \mathrm{~b}$ \\
\hline 82 & & $35.52 \mathrm{~b}$ & & $10.97 \mathrm{~b}$ \\
\hline 83 & & $31.23 \mathrm{~b}$ & $81.82 \mathrm{~b}$ & $06.78 \mathrm{~b}$ \\
\hline 84 & & $26.84 \mathrm{~b}$ & & $02.40 \mathrm{~b}$ \\
\hline 85 & & & $72.43 \mathrm{~b}$ & $42998.27 \mathrm{~b}$ \\
\hline 86 & & & & $93.66 \mathrm{~b}$ \\
\hline 87 & & & $67.67 \mathrm{~b}$ & $89.08 \mathrm{~b}$ \\
\hline 88 & & & & \\
\hline 89 & & & & $79.69 \mathrm{~b}$ \\
\hline
\end{tabular}
$10^{-8} \mathrm{~cm}^{-1}$. Table III gives the wavenumbers of the measured lines for two of the three analyzed bands.

Table III. Wavenumbers for $(13-0)$ and $(13-1)$ bands of $\mathrm{A} \leftarrow \mathrm{X}(\mathrm{b}=$ broad $)$.

$$
A(v=14) \text { level }
$$

(14-0), (14-1), (14-2) and (14-3) bands have been analyzed. Unlike the previously mentioned ones, their structure is quite developed and they are very intense, except (14-2). All the lines are sharp, even for the highest observed values of $J$, and no variation of the $B$-value of the upper level is found. This constant has been deduced accurately from the measurements, since a great number of rotational levels are present: $B_{A(v=14)}=0.07530 \mathrm{~cm}^{-1}$, with $D=3.3 \times 10^{-8} \mathrm{~cm}^{-1}$. Wavenumbers of the (14-0) and (14-1) lines may be found in Table IV.

$$
A(v=15) \text { level }
$$

In bands arising from this level, rotational lines appear from $\mathrm{R}(49)$ and $\mathrm{P}(51)$ on; the first ones 
Table IV. Wavenumbers for $(14-0)$ and $(14-1)$ bands of $\mathrm{A} \leftarrow \mathrm{X}$.

\begin{tabular}{|c|c|c|c|c|}
\hline \multirow[t]{2}{*}{$J$} & \multicolumn{2}{|c|}{$(14-0)$} & \multicolumn{2}{|c|}{$(14-1)$} \\
\hline & $P(J)$ & $R(J)$ & $P(J)$ & $R(J)$ \\
\hline 7 & & 43853.27 & & \\
\hline 8 & 43850.41 & 52.97 & & \\
\hline 9 & 49.77 & 52.63 & & 43425.84 \\
\hline 10 & 49.08 & 52.28 & 43422.27 & \\
\hline 11 & 48.38 & 51.81 & 21.55 & 25.02 \\
\hline 12 & 47.56 & 51.29 & 20.76 & \\
\hline 13 & 46.72 & 50.80 & 19.98 & 24.00 \\
\hline 14 & 45.85 & 50.17 & 19.02 & 23.43 \\
\hline 15 & 44.91 & 49.53 & 18.13 & 22.75 \\
\hline 16 & 43.88 & 48.84 & & 22.07 \\
\hline 17 & 42.83 & 48.07 & 16.09 & 21.34 \\
\hline 18 & 41.73 & 47.24 & & 20.55 \\
\hline 19 & 40.55 & 46.42 & 13.81 & 19.73 \\
\hline 20 & 39.35 & 45.49 & 12.60 & 18.79 \\
\hline 21 & 38.07 & 44.56 & 11.40 & 17.87 \\
\hline 22 & 36.76 & 43.50 & 10.09 & 16.83 \\
\hline 23 & 35.41 & 42.47 & 08.74 & 15.82 \\
\hline 24 & 33.94 & 41.33 & 07.32 & \\
\hline 25 & 32.46 & 40.20 & 05.85 & 13.49 \\
\hline 26 & 30.92 & 38.88 & 04.33 & 12.31 \\
\hline 27 & 29.39 & 37.61 & 02.73 & 11.00 \\
\hline 28 & 27.72 & 36.27 & & 09.70 \\
\hline 29 & 26.00 & 34.88 & 399.43 & 08.33 \\
\hline 30 & 24.29 & 33.46 & 97.74 & 06.91 \\
\hline 31 & 22.47 & 31.96 & 95.97 & 05.43 \\
\hline 32 & 20.60 & 30.40 & 94.11 & 03.93 \\
\hline 33 & 18.74 & 28.80 & 92.24 & 02.33 \\
\hline 34 & 16.75 & 27.13 & 9032. & 00.69 \\
\hline 35 & 14.73 & 25.44 & 88.31 & 398.97 \\
\hline 36 & 12.71 & 23.66 & 86.29 & 97.24 \\
\hline 37 & 10.58 & 21.83 & 84.19 & 95.48 \\
\hline 38 & 08.41 & 19.98 & 82.04 & 93.62 \\
\hline 39 & 06.18 & 18.05 & 79.87 & 91.74 \\
\hline 40 & 03.91 & 16.11 & 77.59 & 89.78 \\
\hline 41 & 01.58 & 14.05 & 75.30 & 87.77 \\
\hline 42 & 799.19 & 11.97 & 72.96 & 85.70 \\
\hline 43 & 96.76 & 09.85 & 70.53 & 83.66 \\
\hline 44 & 94.29 & 07.62 & 68.08 & 81.44 \\
\hline 45 & 91.74 & 05.39 & 65.56 & 79.25 \\
\hline 46 & 89.09 & 03.14 & 63.03 & 76.96 \\
\hline 47 & 86.46 & 00.79 & 60.38 & 74.67 \\
\hline 48 & 83.76 & 79839 & 57.70 & 72.28 \\
\hline 49 & 81.02 & 95.90 & 55.02 & 69.82 \\
\hline 50 & 78.20 & 93.42 & 52.25 & 67.39 \\
\hline 51 & 75.33 & 90.82 & 49.37 & 64.86 \\
\hline 52 & 72.41 & 88.21 & 46.5 .3 & 62.26 \\
\hline 53 & 69.44 & 85.57 & 43.57 & 59.64 \\
\hline 54 & 66.45 & 82.80 & 40.56 & 57.02 \\
\hline 55 & 63.40 & 80.06 & 37.49 & 54.23 \\
\hline 56 & 60.26 & 77.20 & 34.45 & 51.51 \\
\hline 57 & 57.07 & 74.33 & .31 .29 & 48.54 \\
\hline 58 & 53.84 & 71.38 & 28.03 & 4562 \\
\hline 59 & 50.56 & 68.40 & 24.83 & 42.74 \\
\hline 60 & 47.22 & 65.36 & 21.52 & 39.62 \\
\hline 61 & 43.75 & 62.32 & 18.09 & 36.66 \\
\hline 62 & 40.40 & 59.15 & & 33.48 \\
\hline 63 & 36.86 & 55.96 & & 30.35 \\
\hline 64 & 33.30 & 52.70 & & 27.22 \\
\hline 65 & 29.70 & 49.39 & & 23.92 \\
\hline 66 & 26.01 & 46.02 & & 20.53 \\
\hline 67 & 22.35 & 42.60 & & \\
\hline
\end{tabular}

Table IV (continued)

\begin{tabular}{|c|c|c|c|}
\hline \multirow[t]{2}{*}{$J$} & \multicolumn{2}{|c|}{$(14-0)$} & $(14-1)$ \\
\hline & $P(J)$ & $R(J)$ & $R(J)$ \\
\hline 68 & 3718.61 & 43739.20 & \\
\hline 69 & 14.78 & 35.63 & \\
\hline 70 & 11.01 & 32.12 & \\
\hline 71 & 07.01 & 28.43 & \\
\hline 72 & 03.04 & 24.80 & \\
\hline 73 & 699.04 & 21.04 & \\
\hline 74 & 95.00 & 17.31 & \\
\hline 75 & 90.90 & 13.47 & \\
\hline 76 & 86.62 & 09.58 & \\
\hline 77 & 82.41 & 05.70 & \\
\hline 78 & 78.15 & 01.62 & \\
\hline 79 & & 697.65 & \\
\hline 80 & & 93.43 & \\
\hline 81 & & 89.38 & \\
\hline 82 & & & \\
\hline 83 & & 80.93 & \\
\hline
\end{tabular}

are broad, then they become sharper and well defined after $R(63)$ and $P(65)$. The two branches can be observed until $J \cong 115$ for the upper level, but

Table V. Wavenumbers for $(15-0)$ band of $\mathrm{A} \leftarrow \mathrm{X}$ $(\mathrm{b}=$ broad $)$.

\begin{tabular}{|c|c|c|c|c|c|}
\hline$J$ & $P(J)$ & $R(J)$ & $J$ & $P(J)$ & $R(J)$ \\
\hline 49 & & $44044.16 \mathrm{~b}$ & 83 & 43902.45 & 43927.36 \\
\hline 50 & & $41.66 \mathrm{~b}$ & 84 & 897.78 & 23.00 \\
\hline 51 & $44023.67 \mathrm{~b}$ & $39.08 \mathrm{~b}$ & 85 & 93.04 & 18.56 \\
\hline 52 & $20.41 \mathrm{~b}$ & $36.40 \mathrm{~b}$ & 86 & 88.26 & 14.03 \\
\hline 53 & $17.66 \mathrm{~b}$ & $33.66 \mathrm{~b}$ & 87 & 83.42 & 09.51 \\
\hline 54 & $14.68 \mathrm{~b}$ & $30.97 \mathrm{~b}$ & 88 & 78.59 & 04.93 \\
\hline 55 & $11.51 \mathrm{~b}$ & $28.11 \mathrm{~b}$ & 89 & 73.64 & 00.28 \\
\hline 56 & $08.37 \mathrm{~b}$ & $25.27 \mathrm{~b}$ & 90 & 68.58 & 895.55 \\
\hline 57 & $05.15 \mathrm{~b}$ & $22.36 \mathrm{~b}$ & 91 & 63.50 & 90.79 \\
\hline 58 & $01.83 \mathrm{~b}$ & $19.35 \mathrm{~b}$ & 92 & 58.40 & 86.00 \\
\hline 59 & $43998.54 \mathrm{~b}$ & $16.32 \mathrm{~b}$ & 93 & 53.27 & 81.14 \\
\hline 60 & $95.13 \mathrm{~b}$ & $13.25 \mathrm{~b}$ & 94 & 48.07 & 76.15 \\
\hline 61 & $91.73 \mathrm{~b}$ & $10.09 \mathrm{~b}$ & 95 & 42.82 & 71.22 \\
\hline 62 & $88.21 \mathrm{~b}$ & $06.83 \mathrm{~b}$ & 96 & 37.53 & 66.21 \\
\hline 63 & $84.70 \mathrm{~b}$ & 03.63 & 97 & 32.01 & 61.13 \\
\hline 64 & $81.10 \mathrm{~b}$ & 00.38 & 98 & 26.64 & 55.94 \\
\hline 65 & 77.38 & 43997.01 & 99 & 21.15 & 50.79 \\
\hline 66 & 73.73 & 93.59 & 100 & 15.56 & 45.49 \\
\hline 67 & 69.93 & 90.08 & 101 & 09.97 & 40.20 \\
\hline 68 & 66.12 & 86.57 & 102 & 04.38 & 34.88 \\
\hline 69 & 62.24 & 82.99 & 103 & 798.66 & 29.40 \\
\hline 70 & 58.29 & 79.37 & 104 & 92.92 & 23.91 \\
\hline 71 & 54.35 & 75.71 & 105 & 87.10 & 18.49 \\
\hline 72 & 50.29 & 71.96 & 106 & 81.22 & 12.90 \\
\hline 73 & 46.23 & 68.14 & 107 & 75.33 & 07.24 \\
\hline 74 & 42.08 & 64.32 & 108 & 69.41 & 01.60 \\
\hline 75 & 37.90 & 60.41 & 109 & 63.40 & 795.89 \\
\hline 76 & 33.65 & 56.47 & 110 & 57.18 & 90.09 \\
\hline 77 & 29.34 & 52.53 & 111 & 51.12 & 84.20 \\
\hline 78 & 24.97 & 48.43 & 112 & 44.93 & 78.30 \\
\hline 79 & 20.61 & 44.31 & 113 & 38.53 & 72.41 \\
\hline 80 & 16.16 & 40.19 & 114 & 32.18 & 66.43 \\
\hline 81 & 11.65 & 35.94 & 115 & 26.03 & 60.26 \\
\hline 82 & 07.05 & 31.65 & 116 & 19.49 & \\
\hline
\end{tabular}


no broadening of the last lines occurs. The $B$-value of the $A(v=15)$ level is found to be constant and equal to $0.0749 \mathrm{~cm}^{-1}$, the $D$ constant being of the same magnitude as for $A(v=14)$. Wavenumbers of the (15-0) band are listed in Table V.

$$
A(v=16) \text { level }
$$

Wavenumbers of rotational lines of the (16-0) band are given in Table VI. The structure reveals a number of characteristic features:

Table VI. Wavenumbers for $(16-0)$ band of $A \leftarrow X$ $(\mathrm{b}=$ broad $)$.

\begin{tabular}{|c|c|c|c|c|c|}
\hline$J$ & $P(J)$ & $R(J)$ & $J$ & $P(J)$ & $R(J)$ \\
\hline 66 & & $44240.98 \mathrm{~b}$ & 94 & $44092.27 \mathrm{~b}$ & $44119.93 \mathrm{~b}$ \\
\hline 67 & & $37.16 \mathrm{~b}$ & 95 & & $14.69 \mathrm{~b}$ \\
\hline 68 & & 33.37 & 96 & & $09.91 \mathrm{~b}$ \\
\hline 69 & $44209.29 \mathrm{~b}$ & 29.56 & 97 & & $04.70 \mathrm{~b}$ \\
\hline 70 & 05.18 & 25.72 & 98 & & $099.56 \mathrm{~b}$ \\
\hline 71 & 00.93 & 21.82 & 99 & & $94.11 \mathrm{~b}$ \\
\hline 72 & 196.73 & 17.96 & & & \\
\hline 73 & 92.36 & 13.93 & & & \\
\hline 74 & 88.05 & 09.99 & & & \\
\hline 75 & 83.70 & 05.92 & 118 & & 43984.10 \\
\hline 76 & 79.31 & 01.85 & 119 & & 77.59 \\
\hline 77 & 74.85 & $197.69 \mathrm{~b}$ & 120 & 43935.92 & 71.32 \\
\hline 78 & 70.40 & $93.50 \mathrm{~b}$ & 121 & 28.99 & 64.73 \\
\hline 79 & $65.85 \mathrm{~b}$ & $89.30 \mathrm{~b}$ & 122 & 22.15 & 58.29 \\
\hline 80 & $61.25 \mathrm{~b}$ & $85.02 \mathrm{~b}$ & 123 & 15.22 & 51.63 \\
\hline 81 & $56.62 \mathrm{~b}$ & $80.75 \mathrm{~b}$ & 124 & 08.32 & 44.96 \\
\hline 82 & $51.95 \mathrm{~b}$ & $76.38 \mathrm{~b}$ & 125 & 01.28 & 38.27 \\
\hline 83 & $47.14 \mathrm{~b}$ & $71.95 \mathrm{~b}$ & 126 & 894.25 & 31.63 \\
\hline 84 & $42.38 \mathrm{~b}$ & $67.48 \mathrm{~b}$ & 127 & 87.14 & 24.77 \\
\hline 85 & $37.58 \mathrm{~b}$ & $62.91 \mathrm{~b}$ & 128 & 79.99 & 17.84 \\
\hline 86 & $32.69 \mathrm{~b}$ & $58.37 \mathrm{~b}$ & 129 & 72.68 & 10.92 \\
\hline 87 & $27.76 \mathrm{~b}$ & $53.80 \mathrm{~b}$ & 130 & 65.49 & 03.95 \\
\hline 88 & $22.85 \mathrm{~b}$ & $49.06 \mathrm{~b}$ & 131 & 5832 & 896.92 \\
\hline 89 & $17.81 \mathrm{~b}$ & $44.37 \mathrm{~b}$ & 132 & 50.80 & 89.70 \\
\hline 90 & $12.54 \mathrm{~b}$ & $39.61 \mathrm{~b}$ & 133 & & 82.63 \\
\hline 91 & $07.39 \mathrm{~b}$ & $34.75 \mathrm{~b}$ & 134 & 34.88 & 75.39 \\
\hline 92 & $02.41 \mathrm{~b}$ & & 135 & 28.14 & \\
\hline 93 & $097.29 \mathrm{~b}$ & $24.98 \mathrm{~b}$ & 136 & 20.60 & \\
\hline
\end{tabular}

i) The head does not appear in the spectrograms, and rotational lines are observed only beyond $R(66)$ and $P(69)$. The lines from $R(66), R(67)$ and $P(69)$ are broad; the following ones are sharp, and the lines become broad again from $R(77)$ and $P(79)$ on.

ii) Between $J=100$ and $J=119$ concerning the rotational quantum number of the upper level, the lines are very diffuse and no measure can be performed. But for $120 \leqq J \leqq 135$ sharp lines are observed, with intensities decreasing regularly.

iii) The $B$-value of the upper level cannot be regarded as constant versus $J$, even if its variation is fairly slow (see Figure 2). As for the $x_{1}$ level, deperturbed constants for $A(v=16)$ as well as for

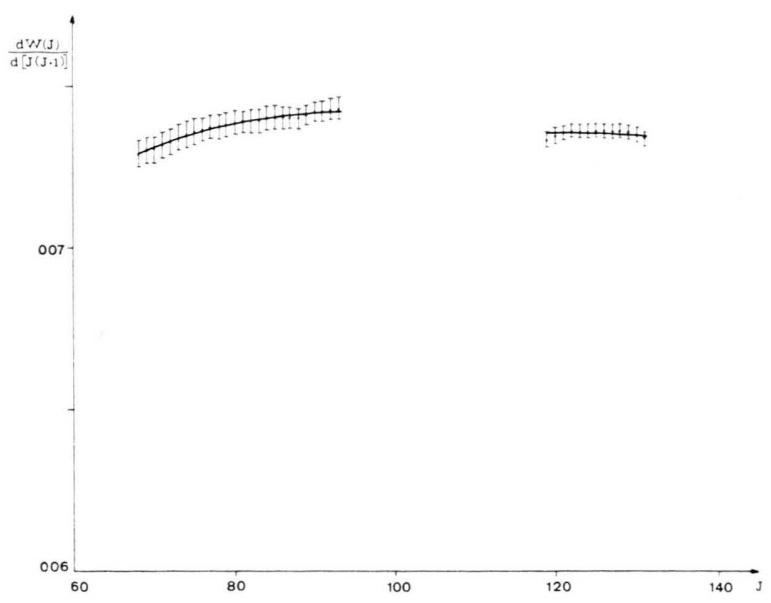

Fig. 2. $B(J)=\mathrm{d} W(J) / \mathrm{d} J(J+1)$ curve for $A(v=16)$ level.

the perturbing level, (noted $x_{2}$ ), have been calculated. The following values are obtained:

$$
\begin{aligned}
T_{\ominus(A, v=16)} & =44349.4 \pm 0.1 \mathrm{~cm}^{-1}, \\
B_{(A, v=13)} & =0.0746 \pm 0.0001 \mathrm{~cm}^{-1}, \\
T_{0 x_{2}} & =44357.8 \pm 0.1 \mathrm{~cm}^{-1}, \\
B_{x_{2}} & =0.0732 \pm 0.0001 \mathrm{~cm}^{-1},
\end{aligned}
$$

the interaction parameter being $0.7 \pm 0.1 \mathrm{~cm}^{-1}$ if the interaction is of the homogeneous type. $T_{0(A, v=16)}$ is in good accordance with the expected value $^{2}$, and $T_{0 x_{2}}$ indicates the occurence of a hitherto unknown level, lying just above $A(v=16)$.

$$
A(v=17) \text { level }
$$

Table VII. Wavenumbers for $(17-0)$ band of $\mathrm{A} \leftarrow \mathrm{X}$.

\begin{tabular}{lrrrrr}
\hline$J$ & \multicolumn{1}{c}{$P(J)$} & $R(J)$ & $J$ & \multicolumn{1}{c}{$P(J)$} & $R(J)$ \\
\hline 12 & 44590.21 & & 30 & 44565.69 & 44574.31 \\
13 & 89.33 & & 31 & 63.74 & 72.70 \\
14 & 88.40 & & 32 & 61.80 & 71.04 \\
15 & 87.40 & & 33 & 59.77 & 69.29 \\
16 & 86.34 & & 34 & 57.69 & 67.51 \\
17 & 85.23 & 4459.21 & 35 & 55.57 & 65.69 \\
18 & 84.09 & 89.33 & 36 & 53.38 & 63.74 \\
19 & 82.86 & 88.40 & 37 & 51.13 & 61.80 \\
20 & 81.58 & 87.40 & 38 & 48.78 & 59.77 \\
21 & 80.23 & 86.34 & 39 & 46.43 & 57.69 \\
22 & 78.86 & 85.23 & 40 & 44.05 & 55.57 \\
23 & 77.40 & 84.09 & 41 & 41.59 & 53.38 \\
24 & 75.88 & 82.86 & 42 & 39.04 & 51.13 \\
25 & 74.31 & 81.58 & 43 & 36.47 & 48.78 \\
26 & 72.70 & 80.23 & 44 & 33.80 & 46.43 \\
27 & 71.04 & 78.86 & 45 & 31.12 & \\
28 & 69.29 & 77.40 & 46 & 28.37 & \\
29 & 67.51 & 75.88 & & & \\
\hline
\end{tabular}


Unlike most of the investigated branches, the head of the (17-0) band is readily observed on the spectrograms. $P$ and $R$ lines, though fsairly diffuse, can be followed up to $R(44)$ and $P(46) . P(J)$ and $R(J+5)$ are superposed, as it may be seen in Table VII. No variation of the $B$-value in the $A(v=17)$ level is observed.

\section{Unidentified $x_{3}$ level}

Between 42360 and $42460 \mathrm{~cm}^{-1}$, two series of lines have been displayed, which may be interpreted

Table VIII. Wavenumbers for $\left(x_{3}-0\right)$ and $\left(x_{3}-1\right)$ bands.

\begin{tabular}{|c|c|c|c|c|}
\hline \multirow[t]{2}{*}{$J$} & \multicolumn{2}{|c|}{$\left(x_{3}-0\right)$} & \multicolumn{2}{|c|}{$\left(x_{3}-1\right)$} \\
\hline & $P(J)$ & $R(J)$ & $P(J)$ & $R(J)$ \\
\hline 31 & & 42465.10 & & 42038.55 \\
\hline 32 & & & & 36.12 \\
\hline 33 & 42451.91 & 60.07 & 42025.41 & 33.67 \\
\hline 34 & & 57.48 & 22.61 & 31.09 \\
\hline 35 & 46.14 & 55.07 & 19.73 & 28.86 \\
\hline 36 & 43.57 & 52.52 & 16.79 & 26.00 \\
\hline 37 & 40.20 & 49.65 & 13.80 & 23.26 \\
\hline 38 & 37.20 & 46.76 & 10.77 & 20.45 \\
\hline 39 & 33.96 & 43.98 & 07.55 & 17.64 \\
\hline 40 & 30.72 & 40.88 & 04.25 & 14.53 \\
\hline 41 & 27.49 & 37.72 & 01.03 & 11.48 \\
\hline 42 & 23.93 & & 41997.59 & 08.13 \\
\hline 43 & 20.46 & 31.25 & 94.04 & 04.96 \\
\hline 44 & 16.91 & 28.23 & 90.72 & 01.62 \\
\hline 45 & 13.14 & 24.77 & 86.90 & 41998.59 \\
\hline 46 & 09.75 & 21.31 & 83.39 & 95.14 \\
\hline 47 & 05.81 & 17.75 & 79.73 & 91.64 \\
\hline 48 & 01.86 & 14.09 & 75.93 & 88.05 \\
\hline 49 & 397.98 & 10.44 & 71.94 & 84.35 \\
\hline 50 & 93.95 & 06.57 & 67.95 & 80.62 \\
\hline 51 & 89.85 & 02.77 & 63.90 & 76.79 \\
\hline 52 & 85.63 & 399.17 & 59.72 & 72.82 \\
\hline 53 & 81.38 & 94.97 & 55.51 & 69.08 \\
\hline 54 & & 90.84 & 51.31 & 64.96 \\
\hline 55 & 72.77 & 86.50 & 46.98 & 60.86 \\
\hline 56 & 68.29 & & 42.54 & \\
\hline 57 & 63.59 & & 37.96 & \\
\hline
\end{tabular}

as the $R(31)$ to $R(55)$ and $P(33)$ to $P(57)$ components of a transition between an unknown $x_{3}$ level and the $(v=0)$ level of the ground state $\mathrm{X}^{1} \Sigma_{\mathrm{g}}{ }^{+}$. No significant variation of the $B$-constant for the $x_{3}$ level is observed within this range of $J$ values $\left(B=0.0627 \mathrm{~cm}^{-1}\right)$, and the $T_{0}$ value $(42500.1$ $\left.\mathrm{cm}^{-1}\right)$ shows that $x_{3}$ lies between $B(v=6)$ and $A(v=9)$ levels. To check this assignment, the rotational structure of the $\left(x_{3}-1\right)$ band has been calculated, and the corresponding lines have been easily recognized on the plates; their wavenumbers are given in Table VIII, together with those for the $\left(x_{3}-0\right)$ band.

\section{Discussion}

Term values $T_{0}$ as well as rotational $B$ and $D$ constants of all the studied vibronic levels are collected in Table IX. The vibrational spacings $\Delta G$ for the $A$ state show a more regular behaviour with respect to $v$ than for $v \leqq 9$. Nevertheless, it must be pointed out that $\Delta G(v=11)$ is too high compared to the other values, which shows that $A(v=11)$ is displaced by an interaction not displayed here. Besides, its $B$-value is smaller than what can be expected from an extrapolation of those belonging to levels $(v=12$ to 16$)$, which decrease regularly with $v$. Despite of these rather small deviations, the achieved results are of great interest, since they allow the determination of deperturbed vibrational and rotational constants for the $A$ state. A leastsquares fitting on $T_{0}$ and $B$ values for $v=12$ to 16 leads to:

$$
\begin{aligned}
T_{00} & =40145.9 \mathrm{~cm}^{-1}, \\
\omega_{\mathrm{e}} & =262.7 \mathrm{~cm}^{-1}, \\
\omega_{\mathrm{e}} x_{\mathrm{\theta}} & =0.48 \mathrm{~cm}^{-1},
\end{aligned}
$$

\begin{tabular}{|c|c|c|c|c|c|c|}
\hline Level & $T_{0} *$ & & $B$ & & & $8 \times D$ \\
\hline$A(v=11)^{x_{3}}$ & $43095.84 \pm 0.04$ & $42500.11 \pm 0.05$ & $0.0746 \pm 0.0001$ & $0.0627 \pm 0.0001$ & - & $3.6 \pm 0.4$ \\
\hline$A(v=12){ }^{x_{1}}$ & $\begin{array}{l}258.8 \\
43354.6 \pm 1.6 \\
250.3\end{array}$ & $43469.4 \pm 1.6$ & $0.0764 \pm 0.0001$ & $0.0633 \pm 0.0001$ & $\sim 12$ & $\sim 12$ \\
\hline$A(v=13)$ & $\begin{array}{l}43604.94 \pm 0.05 \\
248.59\end{array}$ & & $0.0755 \pm 0.0001$ & & $3.8 \pm 0.5$ & \\
\hline$A(v=14)$ & $\begin{array}{l}43853.53 \pm 0.01 \\
249.21\end{array}$ & & $0.07530 \pm 0.00009$ & & $3.1 \pm 0.4$ & \\
\hline$A(v=15)$ & $\begin{array}{l}44102.74 \pm 0.04 \\
246.7\end{array}$ & & $0.0749 \pm 0.0001$ & & $3.0 \pm 0.6$ & \\
\hline$A(v=16)$ & $44349.4 \pm 0.1$ & & $0.0746 \pm 0.0001$ & & $3.1 \pm 0.2$ & \\
\hline$A(v=17)^{x_{2}}$ & $\begin{array}{c}246.9 \\
44596.33 \pm 0.05\end{array}$ & $44357.8 \pm 0.1$ & $0.0734 \pm 0.0001$ & $0.0732 \pm 0.0001$ & - & - \\
\hline
\end{tabular}

Table IX. Term values and rotational constants for the studied levels (in $\mathrm{cm}^{-1}$ ).

* measured above $(v=0)$ level of the ground state $\mathrm{X}^{1} \sum_{\mathrm{g}^{+}}$. 


$$
\begin{aligned}
& B_{\mathrm{e}}=0.0797 \mathrm{~cm}^{-1}, \\
& \alpha_{\mathrm{e}}=0.00031 \mathrm{~cm}^{-1}, \\
& r_{\mathrm{e}}=2.374 \AA .
\end{aligned}
$$

Besides, $D_{\mathrm{e}}$ is approximately equal to $3 \times 10^{-8} \mathrm{~cm}^{-1}$. These results should give reliable initial values for the treatment of the interaction between $A$ and $B$ states.

Two of the three new discovered levels, namely $x_{3}$ and $x_{1}$, may reasonably be thought of as belonging to the same electronic state, since their $B$-values are of the same magnitude. This state should be ${ }^{1} \Sigma_{\mathrm{u}}^{+}$or case $\mathrm{c}-\mathrm{O}_{\mathrm{u}}^{+}$. If the vibrational quantum numbers of $x_{3}$ and $x_{1}$ were $v$ and $v+3$, the $\Delta G$ vibrational spacings would be about $320 \mathrm{~cm}^{-1}$, and if they were $v$ and $v+4$, about $240 \mathrm{~cm}^{-1}$, which is the same magnitude as for the A state. No definitive inference can be made for this point, since trials to display intermediate levels between $x_{3}$ and $x_{1}$ have not been yet successful. On the other hand, it may

* Lebanese National Council for Scientific Research graduate fellow.

1 G. E. Gibson and A. MacFarlane, Phys. Rev. 46, 1058 [1934].

2 A. Topouzkhanian and A. M. Sibaï, Spectrochim. Acta 28 A, 2197 [1972].

, R. J. Donovan and P. Strachan, Trans. Far. Soc. 67. 3407 [1971].

4 G. M. Almy and G. D. Kinzer, Phys. Rev. 47, 721 [1935].

5 G. D. Kinzer and G. M. Almy, Phys. Rev. 52, 814 [1937].

6 P. Perdigon and J. D'Incan, Can. J. Phys. 48, 1140 [1970]. be noted that $x_{2}$ does not belong to the same electronic state as $x_{1}$ and $x_{3}$, since its $B$-value is of a quite different magnitude. Hence, two hitherto unknown electronic states are shown to occur in the energy range $40000-50000 \mathrm{~cm}^{-1}$.

A great number of lines, which appear on our plates in the same spectral region as those studied here, are not attributed. Their classification is now in progress. It should lead to a better knowledge of this rather complex portion of the $\mathrm{As}_{2}$ spectrum. On the other hand, a quite detailed investigation of the broadening of the lines, which has been displayed in most of the vibronic levels investigated here, will be undertaken, in order to explain the predissociation of the $A$ state.

\section{Acknowledgement}

The authors wish to express their sincere appreciation to Dr. J. H. Callomon for his hospitality in allowing them to work in the Spectroscopy Laboratory, Department of Chemistry, University College London.

7 P. Perdigon, F. Martin and J. D'Incan, J. Mol. Spectr. 36, 341 [1970].

8 F. Martin, P. Perdigon, and J. D'Incan, J. Mol. Spectr. to be published.

9 N. A. Finkelstein, Rev. Sci. Instrum. 21, 509 [1950].

10 J. H. Callomon and G. G. Chandler, Appl. Opt. 8, 1133 [1969].

11 J. N. Massot, J. P. Goure, and J. Figuet, J. Phys. B, Atom. Mol. Phys. 6, 1308 [1973]. 